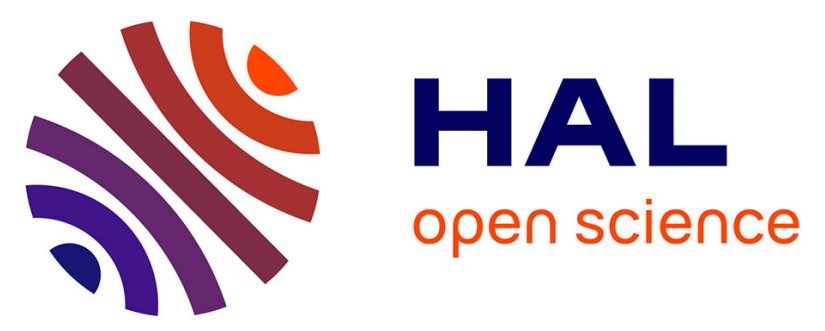

\title{
Bitumen@SiO2 core-shell particles green synthesis towards flowable powdered bitumen and their binder applications
}

\author{
Pauline Anaclet, Martin Depardieu, Eric Laurichesse, Viviane Julien, Yvong \\ Hung, Véronique Schmitt, Renal Backov
}

\section{To cite this version:}

Pauline Anaclet, Martin Depardieu, Eric Laurichesse, Viviane Julien, Yvong Hung, et al.. Bitumen@SiO2 core-shell particles green synthesis towards flowable powdered bitumen and their binder applications. Colloids and Surfaces A: Physicochemical and Engineering Aspects, 2019, 570, pp.531543. 10.1016/j.colsurfa.2019.03.048 . hal-02119061

\section{HAL Id: hal-02119061 \\ https://hal.science/hal-02119061}

Submitted on 22 Oct 2021

HAL is a multi-disciplinary open access archive for the deposit and dissemination of scientific research documents, whether they are published or not. The documents may come from teaching and research institutions in France or abroad, or from public or private research centers.
L'archive ouverte pluridisciplinaire HAL, est destinée au dépôt et à la diffusion de documents scientifiques de niveau recherche, publiés ou non, émanant des établissements d'enseignement et de recherche français ou étrangers, des laboratoires publics ou privés.

\section{()ㅜ(1)}

Distributed under a Creative Commons Attribution - NonCommercial| 4.0 International 


\title{
Bitumen@ $\mathrm{SiO}_{2}$ Core-Shell Particles Green Synthesis towards
}

\section{Flowable Powdered Bitumen and their Binder Applications}

\author{
Pauline Anaclet ${ }^{1,2}$, Martin Depardieu ${ }^{1,3}$, Eric Laurichesse ${ }^{1}$, Viviane Julien ${ }^{2}$, Yvong Hung ${ }^{2}$, \\ Véronique Schmitt ${ }^{*}$ and Rénal Backov ${ }^{1,4^{*}}$
}

${ }^{1}$ CRPP-UMR 5031 Université de Bordeaux CNRS, 115 Avenue Albert Schweitzer, 33600 Pessac, France.schmitt@crpp-bordeaux.cnrs.fr, backov@crpp-bordeaux.cnrs.fr

${ }^{2}$ Present address:Total Marketing Services, Centre de Recherche de Solaize, Chemin du canal-BP22- 69360 Solaize, France.

${ }^{3}$ Present address: University of Bath, Chemistry Department, Claverton Down Bath BA2 7AY, United Kingdom.

${ }^{4}$ Present address: Massachusetts Institute of Technology (MIT), 77 Massachusetts Avenue, office 1-382, Department of Civil and Environmental Engineering, Cambridge, MA02139, USA.backov@mit.edu

\begin{abstract}
Mineralization of flocculated bitumen emulsions allows producing bitumen powders, also referred to as Bitumen@ $\mathrm{SiO}_{2}$ hybrid particles, that can resist storage in hard conditions, with a load up to $8 \mathrm{kPa}$ at $50{ }^{\circ} \mathrm{C}$ during 20 hours, without alteration of their morphology or release of their bitumen core. Thanks to the flocculation, final Bitumen@ $\mathrm{SiO}_{2}$ powders are not highly pulverulent and allow transportation and handling of bitumen at ambient temperature without the need of water as it is the case for bitumen emulsions. This "water free" storage particularity exhibits the double advantage of reducing the cost of transport and of avoiding inhibition of bitumen adhesion at mineral aggregates through the presence of water, therefore rendering the bitumen its high quality of binder. The silica shell is responsible for the high storage stability and, when mixed with aggregates for end use of asphalt, as for example in pavement applications, serves as mineral charge to the bitumen, modifying the bitumen flow properties. Indeed, when heated at $100^{\circ} \mathrm{C}$ and crushed, the capsules break releasing thus the bitumen. This suspension made of bitumen and silica shell fragments exhibits an interesting
\end{abstract}


shear-thinning behavior that can be attributed to the presence of the remnant fragments. Indeed, when shell fragments have been transferred into a silicon oil, initially exhibiting a Newtonian behavior, the mixture of fragments and oil also exhibited a shear thinning rheogram demonstrating the effect of the silica shell fragments. The benefit of such a behavior modification is the possibility to reduce or avoid the usual addition of fillers. Passive adhesion has been tested by generating asphalt concretes with Bitumen@ $\mathrm{SiO}_{2}$ powders and showed high stability. Mechanical tests of cylindrically shaped concretes demonstrate their outstanding mechanical resistance and the high potentiality of the proposed bitumen powders. 


\section{Introduction}

Bitumen is a component issuing from the distillation of a natural product, crude oil, and exhibiting a very high viscosity (in the range of $10^{5}-10^{6} \mathrm{~Pa} . \mathrm{s}$ ) at room temperature [1]. The bitumen viscosity decreases while increasing the temperature, associated with an activation energy of about 50 to $120 \mathrm{~kJ} / \mathrm{mol}$ [2]. Thereby, reaching a viscosity of the order of 1 to $10 \mathrm{~Pa} . \mathrm{s}$ requires heating at a temperature of $120-190^{\circ} \mathrm{C}$. Alternatively, the viscosity can be reduced by formulating the bitumen as the dispersed phase of emulsions. Bitumen emulsions (E) allow thus a homogeneous mix with aggregates at ambient temperature $[3,4]$. As bitumen is the binder between aggregates, the use of emulsions requires the dispersed phase release during the application, so that two antagonistic properties are sought after: emulsions should be stable during storage often under drastic conditions while offering enough instability during mixing with aggregates. This is the reason why usually bitumen emulsions are prepared at their stability limit (in term of surfactant concentration for example) and that they exhibit non long-term stability and require specific storage conditions as a continuous stirring to avoid bitumen drop settling and a temperature of about $40^{\circ} \mathrm{C}$ [5]. Beyond, bitumen emulsions also exhibit intrinsically two main drawbacks. The first one is the fact that bitumen emulsions are composed of at best $70 \mathrm{wt} \%$ of bitumen, meaning that at least $30 \mathrm{wt} \%$ of water has also to be transported and stored. The second drawback is the fact that, owing to both the chemical and porous nature of the mineral aggregates (mainly silicates bearing silanol groups $(\mathrm{Si}-\mathrm{OH}))$, water, rather than highly hydrophobic bitumen, will wet and spread preferentially at the aggregates surface [6]. This thin water layer at the minerals surface may hinder the bitumen wetting and its adhesion at the aggregate surface. Moreover, this thin layer of water is thought to promote the bitumen de-wetting from the aggregates being thereby responsible for roads degradation. This is likely the reason why bitumen 
emulsions are employed only for the secondary traffic roads and not for the roads dedicated to high traffic density such as highways. In this context, it becomes interesting to get rid of the water. Attempts have been proposed in order to provide water-free pellets of bitumen [7-11]. Although the idea was interesting, pellets are usually adhesive and they agglomerate so they cannot be stored in big bags or as piles, the benefit of shaping bitumen into pellets being thus rapidly lost. More recently, we have proposed the synthesis of hybrid organic-inorganic bitumen powders, made of silica shell and bitumen core as a new class of material that easily flows and exhibits the advantages of storage without alteration in severe conditions, while the bitumen properties are recovered for the applications [12,13]. This process, leading to encapsulated bitumen, combines the elaboration of bitumen-in-water Pickering [14] emulsions stabilized by hydophobically-functionalized silica nanoparticles and sol-gel chemistry to create the silica shell around the bitumen core. The capsule dispersions were finally dried through spray-drying. However, these advanced materials suffer the fact that nowadays bitumen emulsions produced at industrial scales are stabilized exclusively with surfactant molecules. It was therefore important to propose the synthesis of the so-called bitumen@ $\mathrm{SiO}_{2}$ core-shell particles composed of a bitumen core and surrounded by a silica shell, making the use of more traditional surfactant-stabilized emulsions. Also in the previous work, we employed a molecular precursor Tetra-Ethyl-Ortho-Silicate (TEOS) to address the sol-gel chemistry. TEOS is an expensive synthetic molecular precursor that required the use of hydrochloric acid $(\mathrm{HCl})$ to set the $\mathrm{pH}$ close to zero.

In the present study, the aim was therefore to show the possibility of: i) synthesizing powdered bitumen made of bitumen@ $\mathrm{SiO}_{2}$ core-shell particles, using more traditional surfactant-stabilized emulsions, ii) suppressing the TEOS and employing alkaline silicate sols as mineral source of the shell while keeping more medium acidic $\mathrm{pH}$ conditions (in the range $3-5)$, iii) reducing the silica amount down to $20 \mathrm{wt} \%$ by provoking the emulsion flocculation 
so that a silica shell coats drop aggregates rather than individual drops to reduce the total surface area and therefore the amount of silica and iv) varying the bitumen origin keeping the same grade to demonstrate the generality of the concept and process. Once produced, the mechanical resistance and properties of the powder were assessed and compared to the initial bitumen. We show that the powder is an efficient binder whatever the aggregate's nature. We demonstrate that, once the shell broken and the bitumen released, the binder exhibits a strong shear thinning behavior that should improve bitumen wetting and spreading at the aggregate surface. Finally, we observe that the new obtained binders exhibit outstanding mechanical properties.

\section{Experimental}

\section{Chemicals}

The cationic surfactant tetradecyltrimethylammonium bromide (TTAB) (Molecular weight, $\mathrm{Mw}=336.39 \mathrm{~g} \cdot \mathrm{mol}^{-1}$ and purity $\geq 99 \%$ ) with a critical micellar concentration (CMC) of 3.5 $10^{-3} \mathrm{~mol} / \mathrm{L}$, the two silica precursors: Tetra-Ethyl-Ortho-Silicate (TEOS) and sodium silicate solution $\left(\sim 27 \% \mathrm{SiO}_{2}\right.$ in $\left.14 \% \mathrm{NaOH}\right)$, as well as hydrochloric acid $37 \mathrm{wt} \%$ were purchased from Sigma-Aldrich and used as received, without further purification. We chose to use sodium silicate as a source of silica because $i$ ) it is less expensive, even after taking into account that $\mathrm{SiO} 2$ only represents $27 \%$ of the solution, ii) it does not release ethanol during synthesis that may destabilize the emulsions and also because iii) it allows working at milder $\mathrm{pH}$ values (see below).

\section{Emulsions}

Among the three studied bitumen-in-water emulsions, two of them have been graciously provided by Laure Boucard and Vincent Gaudefroy from IFSTTAR [15] and one from the 
Total company. They were all obtained from bitumen with penetration grades 160/220 (penetration expressed in $1 / 10 \mathrm{~mm}$ of a $100 \mathrm{~g}$ loaded needle in $100 \mathrm{~g}$ of bitumen after $5 \mathrm{~s}$ at 25 ${ }^{\circ} \mathrm{C}$ standard NF EN 1426) used for road materials from different paraffinic crudes. Bitumenin-water emulsions were prepared with an Emulbitume colloidal mill equipped with the Atomix ${ }^{\circledR}$ mixer. The apparatus consists of two thermo-regulated tanks, one for the aqueous phase and the other for the bituminous binder. Two separate circuits are present on the equipment to keep the phases at the desired temperature. The two phases were then mixed at the level of the Atomix ${ }^{\circledR}$ type turbo-mixer allowing an intense shear by means of a rotor and a stator. A control computer was used to set and control all parameters such as temperature, shear rate and phase pumping speed. The organic phase was heated to $140^{\circ} \mathrm{C}-150^{\circ} \mathrm{C}$ in one of the two preheating tanks. The aqueous phase was heated between 40 and $50^{\circ} \mathrm{C}$. An emulsion with a bitumen content between 65 and 69 wt\% was obtained using an emulsifier concentration of about $4 \mathrm{~kg} /$ ton that is to say about $0.4 \mathrm{wt} \%$ with respect to total emulsion corresponding to typical bitumen emulsion formula used in pavement industry practices (Table 1). The three emulsions reported in Table 1 correspond to three preparations in almost identical conditions showing the degree of reproducibility linked to the bitumen variability and process parameters as the outputs in the Emulbitume.

\section{Emulsions size characterization}

Emulsions were observed using an inverted optical microscope, Zeiss Axiovert X100, and the images were recorded using a Hitachi video camera and Scion image program. The emulsions size distributions were obtained using a Malvern Mastersizer Hydro MS2000 granulometer. The measurements were performed at room temperature in distilled water. The collected scattering intensity as a function of the angle was transformed into a size distribution using the Mie theory. The size distribution was characterized in terms of Sauter diameter D (corresponding to the surface-average diameter) and polydispersity $\mathrm{P}$ : 


$$
\mathrm{D}=\frac{\sum_{\mathrm{i}} \mathrm{N}_{\mathrm{i}} \mathrm{D}_{\mathrm{i}}^{3}}{\sum_{\mathrm{i}} \mathrm{N}_{\mathrm{i}} \mathrm{D}_{\mathrm{i}}^{2}} \quad \text { and } \quad \mathrm{P}=\frac{1}{\overline{\mathrm{D}}} \frac{\sum_{\mathrm{i}} \mathrm{N}_{\mathrm{i}} \mathrm{D}_{\mathrm{i}}^{3}\left|\overline{\mathrm{D}}-\mathrm{D}_{\mathrm{i}}\right|}{\sum_{\mathrm{i}} \mathrm{N}_{\mathrm{i}} \mathrm{D}_{\mathrm{i}}^{3}}
$$

where $N_{i}$ is the total number of droplets with diameter $D_{i} . \bar{D}$ is median diameter, i.e., the diameter for which the cumulative undersized volume fraction is equal to $50 \%$.

Table 1. Emulsion characteristics.

\begin{tabular}{cccc}
\hline Emulsions & Bitumen content $(\mathrm{wt} \%)$ & $\begin{array}{l}\text { TTAB content }(\mathrm{wt} \%) \text { with } \\
\text { respect to the aqueous phase }\end{array}$ & Sauter diameter D $(\mu \mathrm{m})$ \\
\hline E1 & 67 & 1.14 & 4 \\
E2 & 65 & 1.14 & 2 \\
E3 & 69 & 1.14 & 5
\end{tabular}

\section{Tuning the emulsion flocculation}

The native emulsions contained well dispersed droplets (Figure 1 a-c). Such emulsions exhibit a high bitumen/water interface. Indeed, the interfacial areas of the emulsions are equal to $96.6,187.5$ and $79.6 \mathrm{~m}^{2} / \mathrm{m}^{3}$ for respectively the E1, E2 and E3 emulsions (where the density of bitumen has been taken equal to $1.04 \mathrm{~g} / \mathrm{cm}^{3}$ ). This means that if each droplet is mineralized by a shell of silica, the content in silica can become high. In order to decrease this mineral content, the drop size could be increased. However, finely tuning bitumen emulsion drop size remains challenging and we were not able to produce stable enough emulsions with a drop diameter of $10 \mu \mathrm{m}$. Mineralization may alternatively be performed on aggregated drops so that the silica shell includes several drops. This strategy should allow decreasing the final silica content. In order to induce this aggregation, surfactant has been added into the emulsions to provoke depletion governed by attractive interactions between bitumen drops. To determine the adequate concentration of surfactant, different solutions were prepared with surfactant concentrations ranging from 1 to $50 \mathrm{CMC}$. The flocculated solutions were prepared as follows: the surfactant (TTAB) was first dissolved in water at $\mathrm{pH}=2.2$ in order to be in the 
mineralization conditions closed to the silica isoelectric point [16]. Then, the emulsion was added to the previous solution with slight manual stirring. The whole was transferred to a 15 $\mathrm{mL}$ tube which was then placed on a rotating wheel at $20 \mathrm{rpm}$ for one night. A low homogenization promoted the contact between the droplets of bitumen. Each flocculated solution was observed under a microscope (Fig. 1 d-e) in order to obtain flocs with a size between 10 and $100 \mu \mathrm{m}$. Indeed, too big flocs were not looked for because they could block the spray nozzle during spray drying.

Table 2. Composition of flocculated emulsions

\begin{tabular}{ccc}
\hline Emulsions & Bitumen content $(w t \%)$ & $\mathrm{C}_{\text {TTAB }}$ \\
\hline E1f & 37.7 & $40 \mathrm{CMC}$ \\
E2f & 36.6 & $15 \mathrm{CMC}$ \\
E3f & 37.5 & $20 \mathrm{CMC}$
\end{tabular}
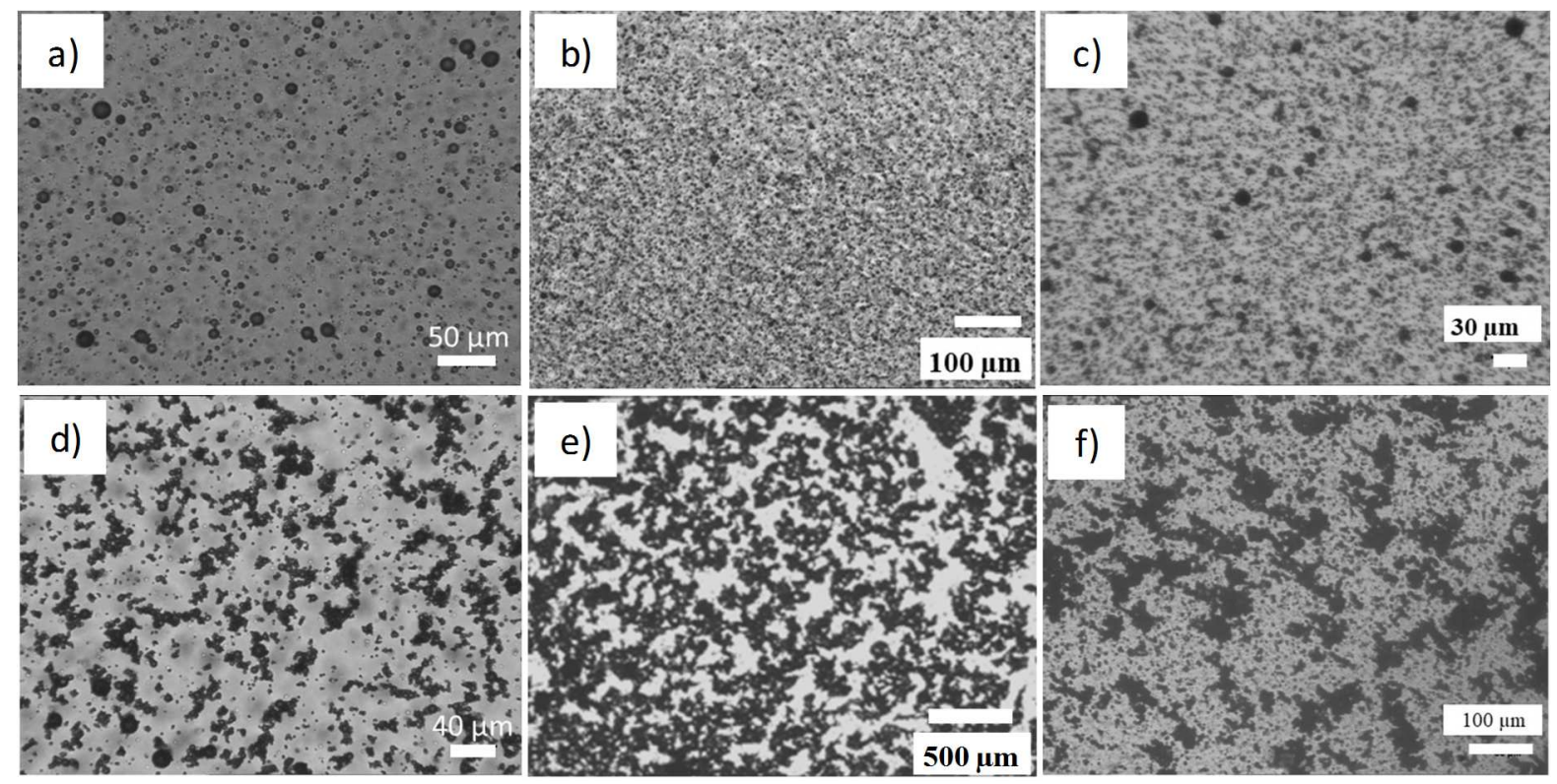

Figure 1. Optical microcopy observation of starting emulsions a) E1, b) E2, c) E3 and corresponding flocculated emulsions d) E1f, e) E2f and f) E3f.

\section{Mineralization Process}

Mineralization with TEOS (E1@ $\left.\mathrm{SiO}_{2}\right)$ 
As bitumen emulsions did not bear too acidic conditions, we chose to proceed mineralization by a two-step process and to pre-hydrolyze the TEOS. So, in a plastic beaker, $5 \mathrm{~g}$ of water at $\mathrm{pH}=2.2$ and $0.74 \mathrm{~g}$ of TEOS were mixed under magnetic stirring at $850 \mathrm{rpm}$ for $2 \mathrm{~h}$ in order to pre-hydrolyze the TEOS. In a second $50 \mathrm{~mL}$ beaker, $2 \mathrm{~g}$ of water at $\mathrm{pH} 2.2$ and $9 \mathrm{~g}$ of E1f were mixed and then the pre-hydrolyzed solution was added under manual stirring. The tubes were then placed on the rotating device at $20 \mathrm{rpm}$ for 3 days. Each tube contained $20.5 \%$ by weight of bitumen. For the second mineralization step, in a beaker, $23 \mathrm{~g}$ of deionized water and $21 \mathrm{~g}$ of hydrochloric acid at $37 \%$ by weight were mixed in order to obtain a solution at a $\mathrm{pH}$ of 0.2 (optimum $\mathrm{pH}$ for the manufacture of dense/Euclidian silica). The already mineralized suspension (suspension after 1st condensation) was then poured into the beaker, and then $1.49 \mathrm{~g}$ of TEOS was added dropwise. The whole was transferred to a $50 \mathrm{~mL}$ tube which was then placed on a rotating device at $20 \mathrm{rpm}$ for one day. Each tube contained $6 \%$ by weight of bitumen. After $24 \mathrm{~h}$, the 2 nd mineralization was considered as complete.

Mineralization with a sodium silicate solution (E2f@ $\mathrm{SiO}_{2}$ and $\mathrm{E} 3 \mathrm{f} @ \mathrm{SiO}_{2}$ )

In a beaker, the distilled water and TTAB (see table 3 for the detailed composition) were mixed and stirred until complete dissolution of the surfactant (TTAB). The emulsion was added under manual stirring, then the mixture was transferred to a $15 \mathrm{~mL}$ tube. This was further shaken on the rotary device one night in order to obtain a homogeneous sample. Once the emulsions were flocculated, they were mineralized. It was observed that depletion induced flocculation was irreversible, likely due to the tendency of bitumen drop to be adhesive. So, the role of depletion was to favor contact between emulsions drops. For the mineralization, the distilled water and the sodium silicate solution were mixed in a beaker. A $1 \mathrm{M}$ aqueous $\mathrm{HCl}$ solution was added until reaching a $\mathrm{pH}$ of 3.4 (for E2f) and 4.3 (for E3f). The flocculated emulsions were then poured under manual stirring and the whole mixtures were transferred to a $250 \mathrm{~mL}$ flask. The flasks were then stirred on rolls one day. After 24 hours, the 
mineralization was considered complete. The flocculation and mineralization conditions are summed up in Table 3. They have been determined and adapted by optical microscopy examination of the flocs and mineralized suspensions.

Table 3. Emulsion compositions during flocculation and mineralization.

\begin{tabular}{cccccccc}
\hline & \multicolumn{3}{c}{ Flocculation } & \multicolumn{3}{c}{ Mineralization } \\
\cline { 2 - 8 } Emulsions & $\begin{array}{c}\text { Distilled } \\
\text { water }(\mathrm{g})\end{array}$ & $\begin{array}{c}\text { TTAB } \\
(\mathrm{g})\end{array}$ & $\begin{array}{c}\text { Emulsion } \\
(\mathrm{g})\end{array}$ & $\begin{array}{c}\text { Distilled } \\
\text { water }(\mathrm{g})\end{array}$ & $\begin{array}{c}\text { Sodium } \\
\text { silicate }(\mathrm{g})\end{array}$ & $\begin{array}{c}\text { Diluted acid } \\
\text { solution } \\
1 \mathrm{M}(\mathrm{g})\end{array}$ & $\begin{array}{c}\text { Flocculated } \\
\text { emulsion }(\mathrm{g})\end{array}$ \\
\hline E2f & 6.8 & 0.2 & 9 & 124.7 & 3.4 & 6.5 & 15.4 \\
E3f & 6.95 & 0.3 & 8.75 & 126.3 & 2 & 6.15 & 15.2 \\
\hline
\end{tabular}

\section{Spray drying process}

Mineralized emulsions have been dried using the spray dryer 4M8-TRIX from ProCept. For $\mathrm{E} 1 @ \mathrm{SiO}_{2}$, as the pH was very acidic and could damage the apparatus, the suspension has been previously washed to raise the $\mathrm{pH}$. This washing step consisted in letting the suspension sediment and replacing the supernatant by distilled water. After this step, the solution exhibited a pH between 5 and 6. For E2 $\mathrm{f} @ \mathrm{SiO}_{2}$ and $\mathrm{E} 3 \mathrm{f} @ \mathrm{SiO}_{2}$, the pH of the suspensions did not require any $\mathrm{pH}$ rise. The process parameters used during the drying of each suspension are given in Table 4.

Table 4. Spray drying parameters.

\begin{tabular}{ccccccc}
\hline $\begin{array}{c}\text { Mineralized } \\
\text { bitumen }\end{array}$ & $\begin{array}{c}\text { Nozzle } \\
\text { size } \\
(\mathrm{mm})\end{array}$ & $\begin{array}{c}\text { Incoming air } \\
\text { flow rate } \\
\left(\mathrm{m}^{3} / \mathrm{min}\right)\end{array}$ & $\begin{array}{c}\text { Temperature } \\
\left({ }^{\circ} \mathrm{C}\right)\end{array}$ & $\begin{array}{c}\text { Cyclone } \\
\text { depressurization } \\
(\mathrm{mbar})\end{array}$ & $\begin{array}{c}\text { Pumping } \\
\text { speed } \\
(\%)\end{array}$ & $\begin{array}{c}\text { Spray air } \\
\text { flow rate } \\
(\mathrm{L} / \mathrm{min})\end{array}$ \\
\hline $\mathrm{E} 1 @ \mathrm{SiO}_{2}$ & 0.8 & 0.3 & 120 & 32.6 & 20 & 7.4 \\
$\mathrm{E} 2 @ \mathrm{SiO}_{2}$ & 0.8 & 0.3 & 120 & 35 & 20 & 8 \\
$\mathrm{E} 3 @ \mathrm{SiO}_{2}$ & 1.0 & 0.3 & 120 & 35 & 40 & 12
\end{tabular}

Final Powders characterization

SEM and Cryo-SEM 
Scanning electron microscopy (SEM) observations were performed on the produced powders by means of a SEM HITACHI TM-1000 apparatus, to visualize the capsules surface. All the samples were gold coated prior to observation. In order to observe the thickness of the shells, cryo-SEM was used. The powder was re-dispersed in distilled water and then a few drops of the suspension were placed in a crucible. This was then immersed in the liquid nitrogen in order to freeze it. The specimen was cut in the SEM preparation chamber to break the sample that has then been observed directly (no replica). If by chance the cut led to a capsule rupture, the observation of the shell thickness was possible. The equipment necessary for the preparation and transfer of samples (ALTO 2500 from GATAN) is directly adapted to SEM (FEG 6700F from JEOL). The sample was slightly sublimed inside the SEM preparation chamber, in order to remove a thin layer of water to better observe the silica shell. It was then covered with a gold-palladium conductive deposit under a stream of argon with a current of $10 \mathrm{~mA}$. Then it was inserted into the observation chamber of the microscope on a plate cooled to $-150^{\circ} \mathrm{C}$. For the observation after capsules rupture, a Hitachi S4500 SEM operating at 10 $\mathrm{kV}$ was used. When required secondary electrons were used with non-coated samples in order to distinguish bitumen that is carbon-rich from the silica shell fragments.

\section{Silica content}

A thermal gravimetric measure was used to determine the amount of inorganics in the powders. The experiments were performed by weighting a sample of powder before and after a thermal treatment at $600^{\circ} \mathrm{C}$ in an oven. The treatment duration corresponded to the delay until no mass evolution could be detected and the sample had completely lost its black color. Bitumen being an organic compound, its mass loss can be observed between 200 and $600{ }^{\circ} \mathrm{C}$ while the inorganic remains until $1000^{\circ} \mathrm{C}$. So, by registration of the mass loss, the proportion of inorganics could be determined. To confirm the silica content, elemental chemical analyses 
were performed through standard flame spectrophotometry by the Crealins company with a ICAP 6000 from ThermoFischer.

\section{Rheology investigations}

In order to compare the viscosity between the pure bitumen grade 160/220 and the bitumen powder manufactured from this bitumen, rheology measurements were carried out on a rheometer of TA instruments ${ }^{\Theta}$ model AR2000 equipped with an ETC oven. This apparatus allows working at temperatures between 50 and $600^{\circ} \mathrm{C}$ under nitrogen flux in order to avoid the oxidation of the bitumen. A plate-plate aluminum geometry with a diameter of $25 \mathrm{~mm}$ was used and the selected gap varied according to the samples. Indeed, the good reproducibility of the loading was complicated and it was therefore necessary to adapt the gap for each load. In order to carry out a measurement on bitumen powder and to make the comparison with initial bitumen possible, it was first necessary to place the powder in a mortar, to heat it at $100^{\circ} \mathrm{C}$ for 30 minutes and then to crush it with the aid of a pestle to obtain a paste. This material was loaded hot on the rheometer and the oven was then regulated at $80^{\circ} \mathrm{C}$. To facilitate the centering of the material under the geometry, we imposed a shear rate of $1 \mathrm{~s}^{-1}$ upon heating. Flow curves were obtained imposing a shear stress ramp whose limits were adapted to the sample. It was generally in the $0.5-2000 \mathrm{~Pa}$ range. We checked that the torque was larger than $1 \mu \mathrm{N} . \mathrm{m}$ and that the bitumen was not ejected from the geometry in order to get reliable measurements.

\section{Mechanical strength tests $\left(90^{\circ} \mathrm{C}\right.$ compression test)}

In order to be stored and conveyed, the bitumen powder must be placed in a one-ton bag with an area of approximately $1.21 \mathrm{~m}^{2}$. This means that the lowest layer of powder in the big-bag is subjected to the maximum pressure exerted by the rest of the big-bag content, which can be estimated at $8.2 \mathrm{kPa}$. However, during storage the powder must not be 
destabilized under this pressure over long periods (several weeks or even several months) with high temperatures, up to $90^{\circ} \mathrm{C}$. In order to evaluate the mechanical strength of the bitumen powder, a homemade device was manufactured. It consisted of a crucible in 2017A (AU4G-duralumin), an alloy composed of $95.5 \%$ aluminum and $4.5 \%$ copper with dimensions of $8.1 \mathrm{~mm}$ in diameter and $1.5 \mathrm{~mm}$ in height, as well as the corresponding indenter. This device allowed to work on a low volume $\left(0.77 \mathrm{~cm}^{3}\right)$, but remained representative of a big-bag since the pressure is an intensive property. After estimation, a weight of $43 \mathrm{~g}$ on the powder is necessary to apply the $8.2 \mathrm{kPa}$ required to mimic the maximum pressure applied in a big-bag. In addition, this type of packaging being generally made from textile fibers, filter paper has been introduced between the powder and the metal. To carry out the test, the powder was placed in the crucible to the brim, then the indenter and the mass were positioned on it. The whole was placed in an oven at $90^{\circ} \mathrm{C}$ for 14 hours to reproduce the severe storage conditions. The chosen time is long enough to ensure that a stationary state has been reached. Indeed, various tests have confirmed the non-dependence over time of the compressive strength after a few hours. At the end of the test, a visual observation allowed determining whether the powder has stuck to the metal revealing a possible bitumen release. Moreover, from the recovery of the product we could know if the powder had been deteriorated, that is to say if the capsules have broken thus releasing the bitumen.

\section{Compression test at Total laboratory $\left(50^{\circ} \mathrm{C}\right.$ compression test)}

For this, the bitumen powder (about $3 \mathrm{~mL}$ ) was placed in a $20 \mathrm{~mL}$ syringe (sealed with silicone) and the piston (without seal) was positioned on the powder. The joint was previously removed. A weight of $208 \mathrm{~g}$ was then deposited over the piston and the whole was put in an oven regulated at $50^{\circ} \mathrm{C}$. As previously, the aim of the experiment was to test the resistance of the powder to an applied pressure of $8 \mathrm{kPa}$ (the pressure applied by one big bag) at $50^{\circ} \mathrm{C}$ for 
20 hours. After the experiment, the powder was removed from the syringe and examined to determine if it resisted compression. Indeed, there was almost no loss on the syringe and the recovered powder was initially compact but the grains could easily be separated showing that the capsules were intact.

\section{Aggregate coating experiments}

To test the coating properties of the bitumen powder, experiments were carried out on a small scale (asphalt mix of $1 \mathrm{~kg}$ ) using as an aggregate a mixture of different La Noubleau granular slices (Table 5) and using a Kitchen Aid as a kneader.

Table 5. Granular slices composition. Grav. $\mathrm{i} / \mathrm{j}$ means a size comprised between $\mathrm{i}$ and $\mathrm{j} \mathrm{mm}$.

\begin{tabular}{ccc}
\hline Type & Origin & Wt\% \\
\hline Sand 0/2 & La Noubleau & 39 \\
Grav. 2/4 & La Noubleau & 10 \\
Grav. 4/6 & La Noubleau & 12 \\
Grav. 6/10 & La Noubleau & 38 \\
filler & La Noubleau & 1
\end{tabular}

E2f@ $\mathrm{SiO}_{2}$ (process 1)

The aggregates were heated to $125^{\circ} \mathrm{C}$ and the bitumen powder was added without heating (60.2 g, representing $5.7 \mathrm{wt} \%$ of bitumen powder in the asphalt concrete). Using the Kitchen Aid, a first kneading was performed. However, the mixture, brown in color, seemed dry, with no shine or sticky effect showing that bitumen has not been released. So, it was heated again at $145^{\circ} \mathrm{C}$ and then re-kneaded. The asphalt concrete changed color from brown to black, but no gloss or sticky effect was noticed. A final heating at $160{ }^{\circ} \mathrm{C}$ overnight was carried out followed by kneading. The asphalt concrete seemed correct (shine and sticky effect).

E2f@ $\mathrm{SiO}_{2}($ process 2) 
For $\mathrm{E} 2 \mathrm{f} @ \mathrm{SiO}_{2}$ (process 2), the aggregates and the powder $(64.25 \mathrm{~g}$, ie $6.0 \mathrm{wt} \%$ of bitumen powder in the asphalt concrete) were heated to $160^{\circ} \mathrm{C}$ for 2 hours. The first mixing seemed promising compared to the first test. However, the asphalt appeared still dry and nonsticky. After several heating and mixing cycles, the asphalt concrete appeared to be correct as the aggregates were well covered, glossy and sticky.

\section{$\mathrm{E} 3 \mathrm{f} @ \mathrm{SiO}_{2}$}

Four types of mixes (of small quantities, $40 \mathrm{~g}$ ) were obtained from different types of aggregates. To do so, $37.4 \mathrm{~g}$ of aggregates (limestone, flint, quartzite or diorite 6/10) and $2.65 \mathrm{~g}$ of powder (representing $5.55 \%$ by weight of bitumen) were weighted in a metal bowl and then placed in an oven at $160^{\circ} \mathrm{C}$ for $1 \mathrm{~h}$. Manual stirring with a spatula was then applied. The coating of the aggregates being difficult, the bowl was returned to the oven at $160^{\circ} \mathrm{C}$ for 20 min and further stirring was applied until the aggregates were coated. The bitumen powder was able to coat the 4 types of aggregates.

\section{Test of pieces generation and mechanical tests.}

Asphalt concrete is intended to be placed on a road and therefore it has to withstand the compression due to road traffic. Once the asphalt manufactured, it has therefore to be transformed into a cylindrical test piece in order to test its resistance to compression. To address the produced material performances, the hot mixture $(1 \mathrm{~kg})$ was placed in a mold and was then compacted using a Controlab press in order to obtain a test piece. A pre-compaction was first performed, then a force of $60 \mathrm{kN}$ was applied for 300 seconds. The assembly (mold and compacted asphalt concrete) was then allowed to cool in order to recover the test piece. The different test pieces were then characterized by measuring their dimensions and masses. They were then compressed axially and crushed at a predetermined speed until rupture to determine the maximum crushing force they can bear. This test aimed at determining the 
compressive strength of the mixes. Note that these tests exhibit the same characteristics of the so-called Duriez tests but as they were only conducted in air rather than in air and water, we prefer avoiding the term Duriez test in the following.

\section{Passive adhesion test}

Asphalt is subjected to climate variations, it is therefore useful to check the bitumen adhesion on aggregates. Passive adhesion test were carried out following the NF EN 15626 standard in order to determine whether bitumen is removed or not from the aggregates in presence of water and under heating. Asphalt was put in demineralized water heated at $60^{\circ} \mathrm{C}$ for several hours ( $24 \mathrm{~h}$ in the present case). Then the sample was visually examined to detect the possible stripping of bitumen.

\section{Results and discussion}

Emulsion E1 has been mineralized with TEOS precursor using the two-step procedure described in the materials and methods section. After drying a fine powder has been obtained (Figure 2). This powder composed of bitumen@ $\mathrm{SiO}_{2}$ core-shell particles exhibited a high mechanical resistance (can support a pressure of around $8.1 \mathrm{kPa}$ ) that was a key property for long term storage and preserved its ability to deliver the bitumen under both a mechanical shear and a temperature increase which are required for its use. The initial emulsion was composed of well dispersed drops. By comparing the size of the powder grains with the drops sizes, despite the large size distribution, one can conclude that individual drops have been mineralized. From TEM observations, the shell thickness can be estimated between 85 and $150 \mathrm{~nm}$ (Figure 2c). 

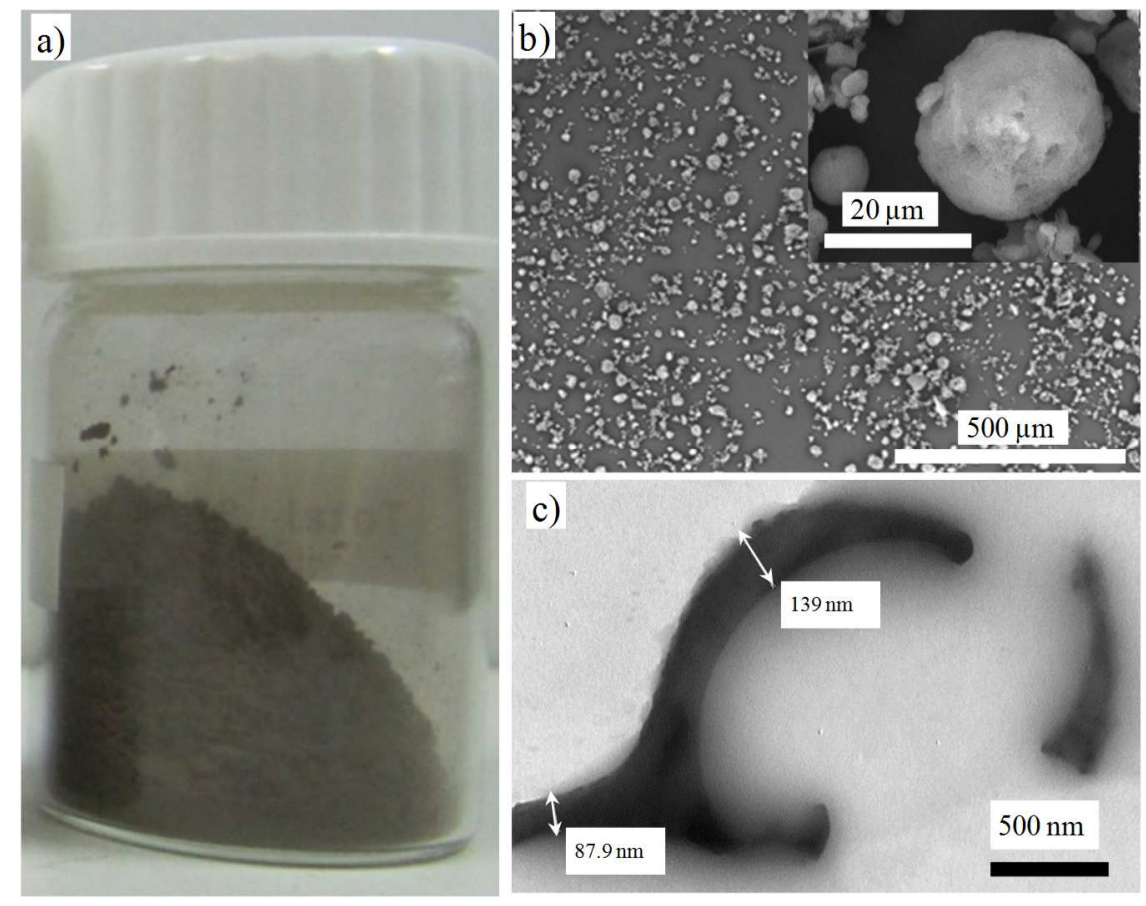

Figure 2. a) E1f@ $\mathrm{SiO}_{2}$ bitumen powder obtained by mineralizing each single E1 emulsion droplet using TEOS as a silica precursor, b) SEM picture of mineralized E1, c) E1 @ $\mathrm{SiO}_{2}$ TEM (the E1@ $\mathrm{SiO}_{2}$ core shell particles were dispersed in an Epoxy resin followed with a microtome cut).

From pure geometric considerations, the silica volume fraction can be written as followed:

$$
\frac{\mathrm{V}_{\text {silica }}}{\mathrm{V}_{\text {total }}}=\phi_{\mathrm{s}}^{\mathrm{v}} \approx \frac{\mathrm{S} * \mathrm{e}}{\mathrm{V}_{\text {total }}}=\frac{3 \phi_{\text {bitumen }}^{\mathrm{v}} * \mathrm{e}}{\mathrm{R}}
$$

where $\mathrm{S}$ is the surface area (unit: $\mathrm{m}^{2}$ ), e represents the silica shell thickness (unit: $\mathrm{m}$ ) with the assumption that $\mathrm{e}<<\mathrm{R}, \mathrm{V}_{\text {total }}$ is the total volume of sample (unit: $\mathrm{m} 3$ ) $\phi_{\text {bitumen }}^{v}$ is the bitumen volume fraction (no unit) and $\mathrm{R}$ the bitumen core average radius (unit: $\mathrm{m}$ ). As a consequence, the thickness can be expressed as:

$$
\mathrm{e} \approx \frac{\phi_{\mathrm{s}}^{\mathrm{m}} * \rho_{\mathrm{b}} * \mathrm{R}}{3 * \rho_{\mathrm{s}} *\left(1-\phi_{\mathrm{s}}^{\mathrm{m}}\right)}
$$

where the bitumen and silica density is respectively equal to $\rho_{b}=1.04 \mathrm{~kg} / \mathrm{m}^{3}$ and $\rho_{s}=1.6$ $\mathrm{kg} / \mathrm{m}^{3}$ (the silica density has been measured by helium pycnometry, silica has been synthesized in presence of micelles explaining such a low value, much smaller than 2.1). Thermogravimetry as well as elementary analyses gave a silica mass fraction of 0.3 
(corresponding to a volume fraction of 0.22 ), a value larger than a reasonable limit of $20 \mathrm{wt} \%$ (corresponding to a volume fraction of 0.14$)$ ). Using equation 2 and with the values $R=2 \mu \mathrm{m}$ (E1 table 1), e is around $186 \mathrm{~nm}$. Note that this value is really lower than R, validating the approximation. This average thickness is in good agreement with the values found with TEM (Figure 2c). This first synthetic path demonstrates that a limit toward the silica shell thickness has been reached for $\mathrm{E} 1 @ \mathrm{SiO}_{2}$ bitumen powder since decreasing the silica content would lead to too fragile shells. As we cannot decrease further the silica shell thickness to diminish the silica content from 30 to $20 \mathrm{wt} \%$, the idea was to decrease the silica surface by increasing the amount of embedded bitumen. Thereby we have induced a rational depletion-based flocculation of the initial emulsions E2 (Figure $3 \mathrm{a}, \mathrm{b}$ ) and E3. Additionally, we chose to use a silicate solution instead of TEOS as mineral source and meanwhile adjusting the $\mathrm{pH}$ at 3.4.
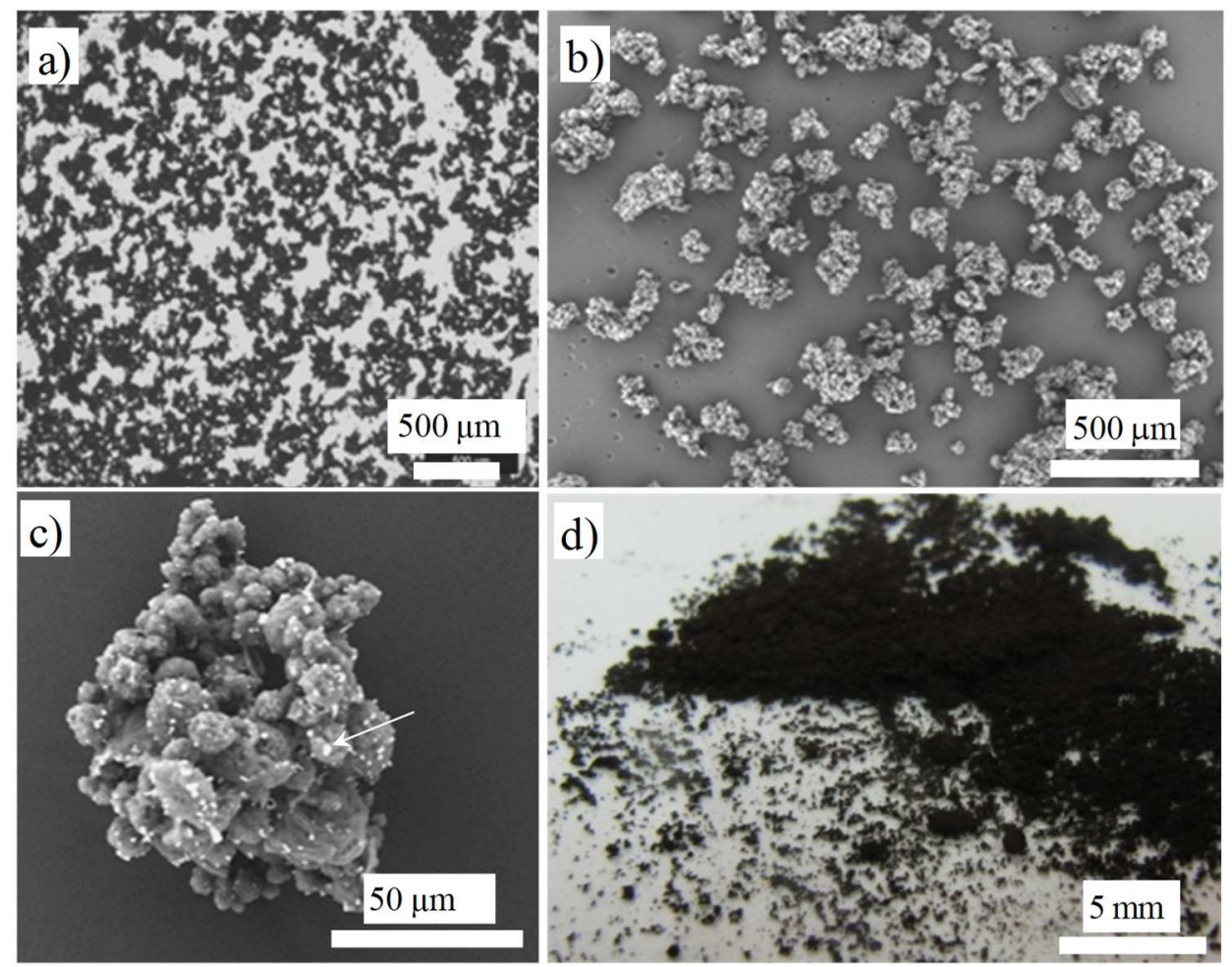

Figure 3. Example of final obtained $\mathrm{E} 2 \mathrm{f} @ \mathrm{SiO}_{2}$ bitumen powder obtained through the use of a flocculated emulsion and a silicate solution as a mineral source. a) starting flocculated emulsion E2f, b-c) E2f@ $\mathrm{SiO}_{2}$ bitumen powder observed trough SEM (the white arrow indicates a $\mathrm{NaCl}$ crystal), d) picture of flowable E2 $\mathrm{f} @ \mathrm{SiO}_{2}$ bitumen powder. 
The mineralized emulsions have been dried using a spray dryer as described in the materials and methods section. The final products $\mathrm{E} 2 \mathrm{f} @ \mathrm{SiO}_{2}$ and $\mathrm{E} 3 \mathrm{f} @ \mathrm{SiO}_{2}$ were flowable powders (Figure 3d) in which agglomerates of mineralized bitumen droplets could be observed through SEM (Figure 3b,c). In order to determine the silica shell thickness, we have performed Cryo-SEM (Figure 4).

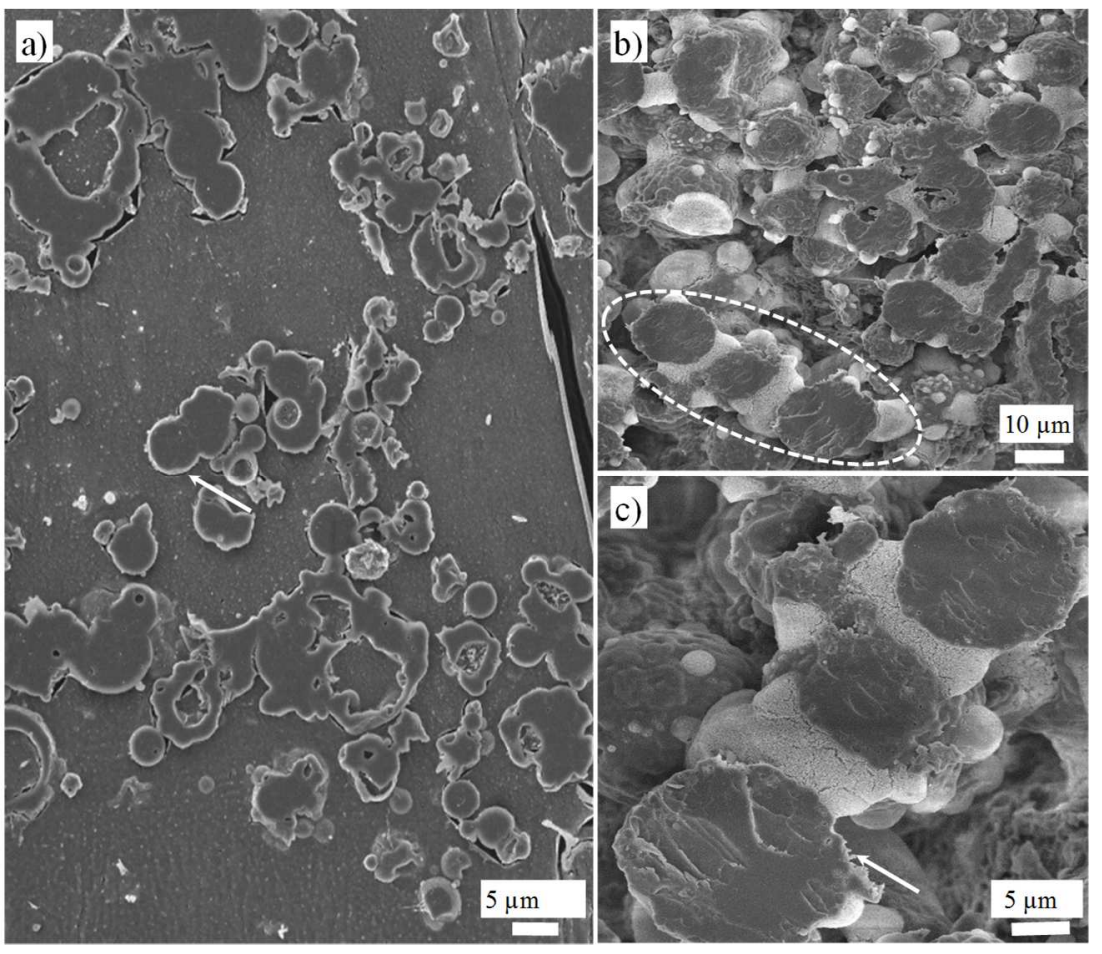

Figure 4. Cryo-SEM of final obtained E3f@ $\mathrm{SiO}_{2}$ a) and $\mathrm{E} 2 \mathrm{f} @ \mathrm{SiO}_{2}$ b,c) bitumen powders obtained through the use of a flocculated emulsion and a silicate solution as a mineral source. The materials have been cut through microtome prior to SEM observations. The focused dashed zone of $b$ ) is represented within $c$ ). The white arrow indicates the silica shell bearing a thickness around 150-200 $\mathrm{nm}$. Note that in b and c, the white bulky phase between the powder grains is likely ice. Indeed, in presence of $\mathrm{NaCl}$ the eutectic temperature is decreased and vitrification of remaining water is more difficult to achieve. The effective shape of the silica shell are better evidenced in Figure 6 e,f.

We can observe the mineralization of agglomerates of bitumen droplets with a surrounding silica shell exhibiting a thickness around 150-200 $\mathrm{nm}$. The amount of inorganic content present within the powders has been assessed using thermo-gravimetry (determination 
of the remaining weight fraction at $600{ }^{\circ} \mathrm{C}$ in an oven as described in the experimental part). It is equal to 17-18 wt\% and $16 \mathrm{wt} \%$ for the $\mathrm{E} 2 \mathrm{f} @ \mathrm{SiO}_{2}$ and $\mathrm{E} 3 \mathrm{f} @ \mathrm{SiO}_{2}$ bitumen powders respectively. We have to underline that this amount of inorganic matter is a mixture of silica and $\mathrm{NaCl}$ salt since the mineral source is a sodium silicate solution. Elementary analyses allow distinguishing the two mineral sources: E2f@ $\mathrm{SiO}_{2}$ contains $11 \mathrm{wt} \%$ of silica and $7 \mathrm{wt} \%$ of $\mathrm{NaCl}$, while $\mathrm{E} 3 \mathrm{f} @ \mathrm{SiO}_{2}$ contains 13 wt $\%$ of silica and $9 \mathrm{wt} \%$ of $\mathrm{NaCl}$. Even if the two methods do not give exactly the same results for $\mathrm{E} 3 \mathrm{f} @ \mathrm{SiO}_{2}$, the amount of mineral are consistent. The as-synthesized mineralized bitumen have been designed to support a pressure of $8 \mathrm{kPa}$ at $50^{\circ} \mathrm{C}$ while being still flowable once the pressure is released and the temperature decreased. For this evaluation, the hybrid powders $\mathrm{E} 2 \mathrm{f} @ \mathrm{SiO}_{2}$ were placed in a syringe under a weight of $208 \mathrm{~g}$ (that corresponds to a pressure of $8 \mathrm{kPa}$ ) and placed into an oven at $50^{\circ} \mathrm{C}$ during 20 hours (Figure 5).

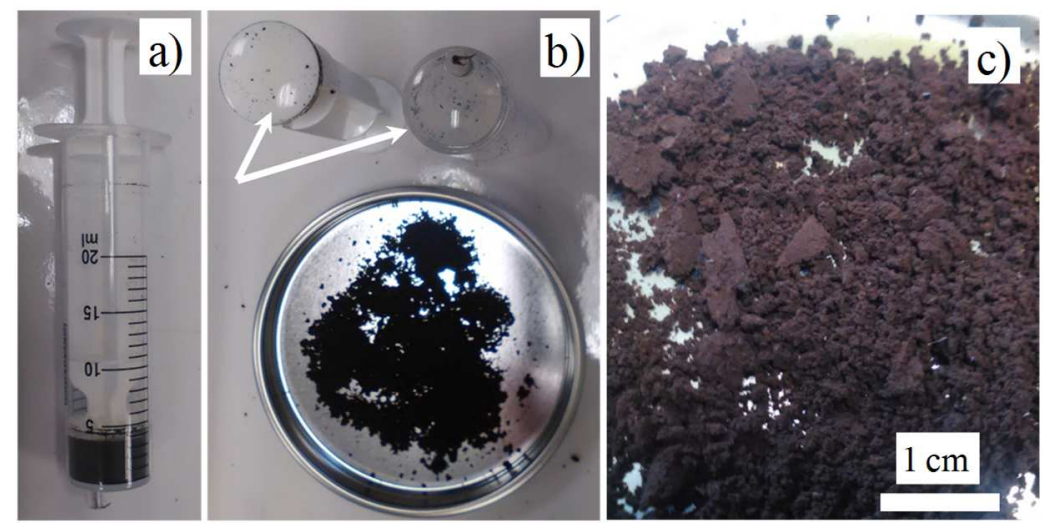

Figure 5. Example of a mechanical test at $50^{\circ} \mathrm{C}$ and behavior for the $\mathrm{E} 2 \mathrm{f} @ \mathrm{SiO}_{2}$ bitumen powder obtained through the use of a flocculated emulsion and a silicate solution as a mineral source, a) compressed powder in the syringe after removal of the weight, b) after compression the piston as well as the bottom of the syringe (white arrows) are clean and free of sticky bitumen showing the resistance of the powder to mechanical compression, c) flowable bitumen after the thermo-mechanical treatment.

After this treatment the powders were compacted but not destabilized and they kept their flowable character (Figure 5c) without sticking to the piston or the syringe bottom that were in direct contact with the powder during compression at $50^{\circ} \mathrm{C}$. These two surfaces were 
not contaminated with bitumen (Figure 5b), meaning that no bitumen has been released and that the core-shell nature of these objects was preserved.

The mechanical resistance at $50^{\circ} \mathrm{C}$ is required for storage; however, for use, bitumen should be released at higher temperature and under shear to regain his adhesive behavior. It is then worthy investigating the flow properties of the final product after bitumen release, corresponding to the material in contact with aggregates. To get insight into the flow behavior, we performed rheology investigations on the initial bitumen and on this novel bitumen containing the inorganic broken shells (see Materials and methods section for the experimental conditions applied to break the shells and Figure 6a for the results). These experiments were carried on at $80^{\circ} \mathrm{C}$. 

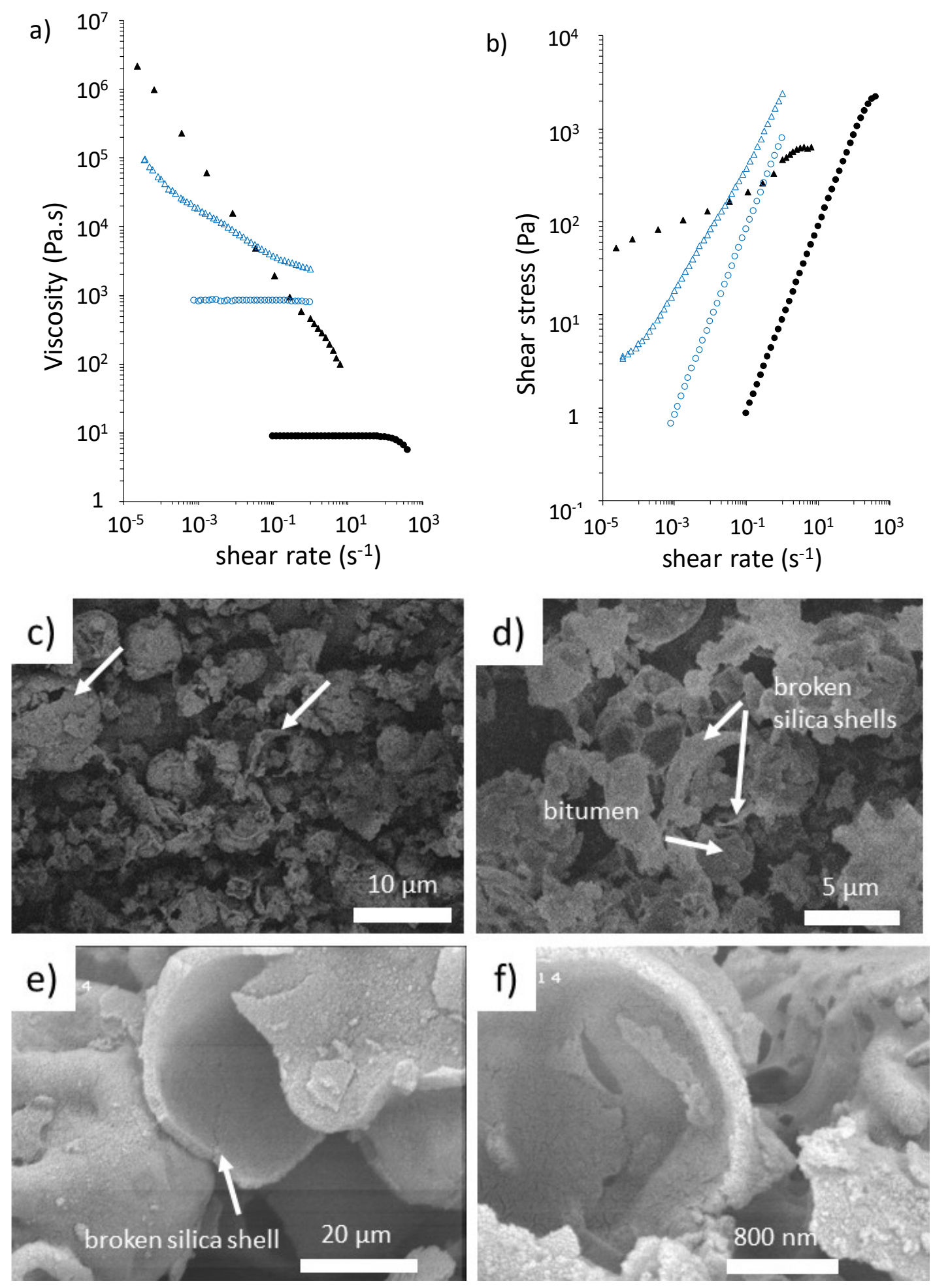

Figure 6. Rheology and SEM investigations: a) viscosity versus shear rate and b) shear stress versus shear rate for: the initial bitumen (grade 160/220), $\boldsymbol{\Delta}$ the bitumen released from the powder obtained with $\mathrm{E} 3 \mathrm{f} @ \mathrm{SiO}_{2}$ after crushing and heating at $100^{\circ} \mathrm{C}$, $\bigcirc$ Rhodorsil oil 48V1000000, $\triangle$ Rhodorsil oil 48V1000000 containing the inorganic shell from $\mathrm{E} 3 \mathrm{f} @ \mathrm{SiO}_{2}$ bitumen powder and. c-f) SEM images of a resulting E3f@ $\mathrm{SiO}_{2}$ bitumen powder after being sheared in a mortar by hand while being heating at $100^{\circ} \mathrm{C}$. The resulting composite material has been washed three times with toluene in order to remove a part of the bitumen and get a 
brownish pulverulent powder. The granular aspect in Fig. e-f comes from the metallization step.

The viscosity versus the shear rate is reported in Figure 6a for pure bitumen and for bitumen released from powder $\mathrm{E} 3 \mathrm{f} @ \mathrm{SiO}_{2}$ by hand shearing using a mortar and pestle at $100^{\circ} \mathrm{C}$. The native bitumen exhibits a Newtonian plateau from 0.1 to $70 \mathrm{~s}^{-1}$ at a viscosity of 10 Pa.s. For higher shear rates, a shear thinning behavior is observed, which is a classical behavior for bitumen [17]. The crushed $\mathrm{E} 3 \mathrm{f} @ \mathrm{SiO}_{2}$ bitumen powder exhibits a much higher viscosity and a shear thinning behavior in the whole explored range (from $10^{-5}$ to $10 \mathrm{~s}^{-1}$ ). We hypothesize that the broken inorganic silica shell fragments of the $\mathrm{E} 3 \mathrm{f} @ \mathrm{SiO}_{2}$ bitumen powder strongly contributes to the observed behavior. In the one hand, they act as mineral charges (16 wt $\%$ of charges) increasing the viscosity and on the other hand as they may have lost their isotropic shape, they may align in the shear, promoting shear thinning even a low shear rates. To observe the shell fragments, we have reproduced the same crushing experiment of E3f@ $\mathrm{SiO}_{2}$ bitumen powder at $100^{\circ} \mathrm{C}$ in a mortar and tried washing three times the released bitumen with toluene to recover the broken silica shell fragments before observing them by SEM (Figure 6b-d). We can notice a certain anisotropy where 2D shell broken shells can be observed at least as hemi spheres. To check the effect of the silica fragment, we mixed 15 wt\% of the recovered brown powder made of silica shell and remaining bitumen with a silicone oil (1000 Pa.s at $\left.25^{\circ} \mathrm{C}\right)$ and measured the rheograms of both the oil and the oil containing silica. We can notice that the viscosity of the oil is constant while the same oil containing broken silica shells exhibits both a higher initial viscosity and a shear thinning behavior (Figure 6). As the shear thinning regime is only observed in presence of the shell fragments, it can be concluded that the shear thinning behavior of both powdered bitumen and charged oil originates from the presence of silica shell fragments. It can also be noticed that 
even if the Newtonian viscosity of the bitumen is lower than the one of oil, the shear thinning effect of the mineral fragments is much stronger for the bitumen. These properties (higher viscosity and shear thinning behavior) is of special interest for applications. Indeed, in asphalt it is common to add very fine particles of sand called fillers [18-20] or other mineral charges $[21,22]$. The presence of the silica shells already plays the role of such fillers so that their addition could be suppressed or at least reduced with the proposed bitumen powder. Moreover, in many cases, authors are looking for anisotropic particles like glass fibers...[2325]

After release, the bitumen has to act as a binder therefore we tested the $\mathrm{E} 2 \mathrm{f} @ \mathrm{SiO}_{2}$ and E3f@ $\mathrm{SiO}_{2}$ bitumen powders ability to stick aggregates. Also if adhesion is not good enough e binder can undergo moisture damage [26]. Example of $\mathrm{E} 2 \mathrm{f} @ \mathrm{SiO}_{2}$ binding process is proposed in Figure 7 a-c.
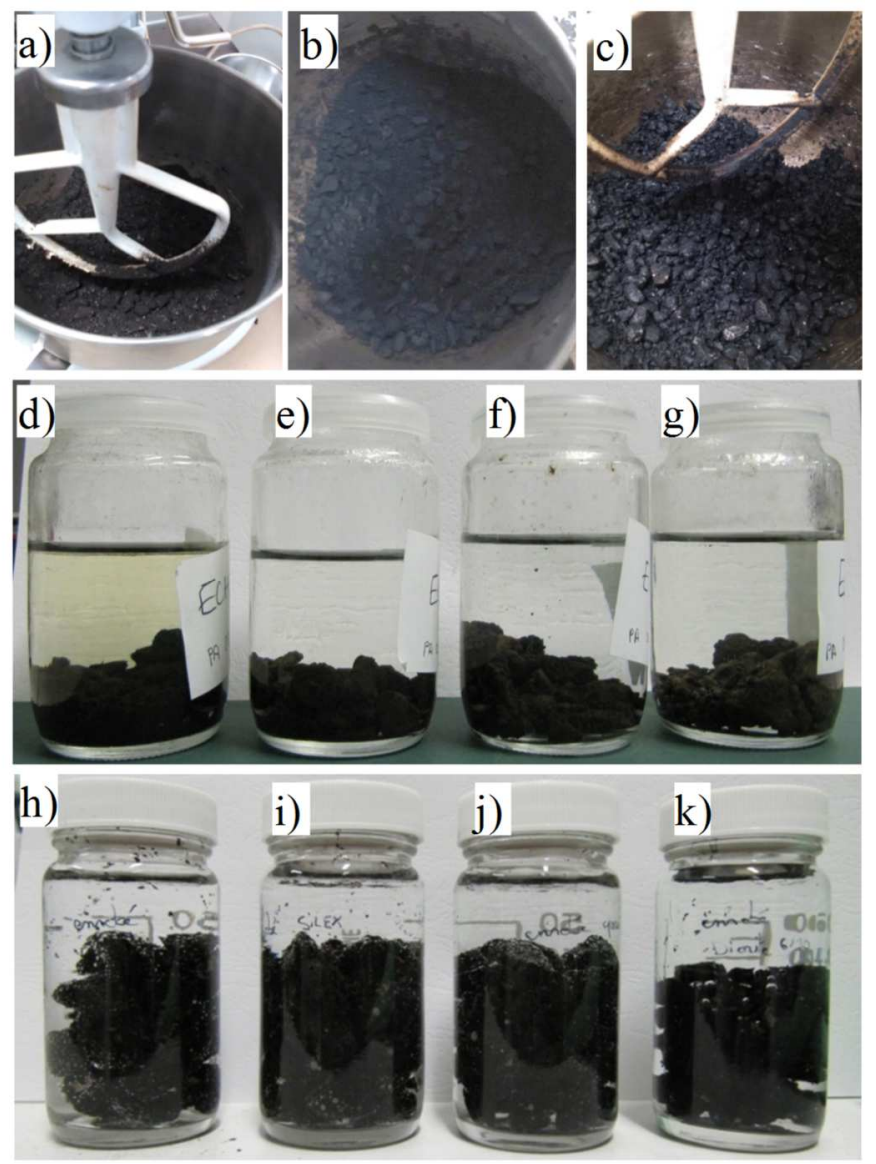
Figure 7. Asphalt concrete generation and passive adhesion tests. a-c) process of mixing the $\mathrm{E} 2 \mathrm{f} @ \mathrm{SiO}_{2}$ (process 1) powder with aggregates. a) illustration of the mixing of $\mathrm{E} 2 \mathrm{f} @ \mathrm{SiO}_{2}$ powder and aggregates, previously heated at $145^{\circ} \mathrm{C}$, with the Kitchen aid b) resulting mixture, no shiny and sticky aspect can be observed c) resulting asphalt concrete at $160^{\circ} \mathrm{C}$ exhibiting both a shining and sticky aspect. d-e) E2@ $\mathrm{SiO}_{2}$ asphalt concrete passive adhesive tests after two months, d) E2f@ $\mathrm{SiO}_{2}$ asphalt concrete obtained by process 1, e) E2f@ $\mathrm{SiO}_{2}$ asphalt concrete obtained by process 2, f) asphalt concrete made of bitumen (160/220) and aggregates, g) asphalt concrete made of a harder bitumen (penetration grade 50/70) and aggregates. h-k) E3f@ $\mathrm{SiO}_{2}$ asphalt concrete passive adhesive tests in distilled water at 24 hours at $60^{\circ} \mathrm{C}$ with diverse aggregate natures, h) limestone, i) flint, j) quartzite, k) diorite.

As two antagonistic effects were sought after, that is to say a high mechanical and thermal resistance for storage together with a possible release for application, we had to optimize the binding process to really reach the desired adhesive and shining aggregates coated with bitumen. A first process (process 1) made the use of a first heating temperature of the aggregates $\left(145^{\circ} \mathrm{C}\right)$ into which the $\mathrm{E} 2 \mathrm{f} @ \mathrm{SiO}_{2}$ powder was added. The obtained asphalt concrete was not adhesive enough because the bitumen was not completely recovered (Fig. $7 \mathrm{~b}$ ), so we increased the heating temperature to $160^{\circ} \mathrm{C}$ for several hours. As it can be seen from Figure $7 \mathrm{c}$, the final asphalt concrete was homogeneous, shining and adhesive. The obtained asphalt concretes obtained through the two processes were tested against passive adhesion tests (Figure $7 \mathrm{~d}$-e) and compared with asphalt concrete obtained from pure bitumen (Figure $7 \mathrm{f}-\mathrm{g}$ ). We can see the asphalt concrete obtained through the process 1 generates after two months a yellowish coloration of the water in which it was immerged, revealing that the bitumen/aggregates coating is not optimized, we hypothesize that this color arose from the prolonged heating at $160^{\circ} \mathrm{C}$. Indeed, this coloration is not observed when process 2 is employed (Fig. 7e) similarly to the case for the asphalt concretes obtained with pure bitumen as binder (Fig. $7 \mathrm{f}, \mathrm{g}$ ). This feature indicates that under the process 2 the $\mathrm{E} 2 \mathrm{f} @ \mathrm{SiO}_{2}$ allows promoting a good wetting and coating of the aggregates.

To go further and test the resistance of the asphalt concretes, we have produced bulky cylindrical shaped compacted asphalt concretes based on the two preparation processes and 
compared them using two pure bitumen with two distinct penetration grades: 160/220 which is the bitumen at the origin of the powder $\mathrm{E} 2 \mathrm{f} @ \mathrm{SiO}_{2}$ and a harder one with a 50/70 penetration grade (Fig. 8). Mechanical tests have been performed following the description reported in the materials and methods section (Table 5).
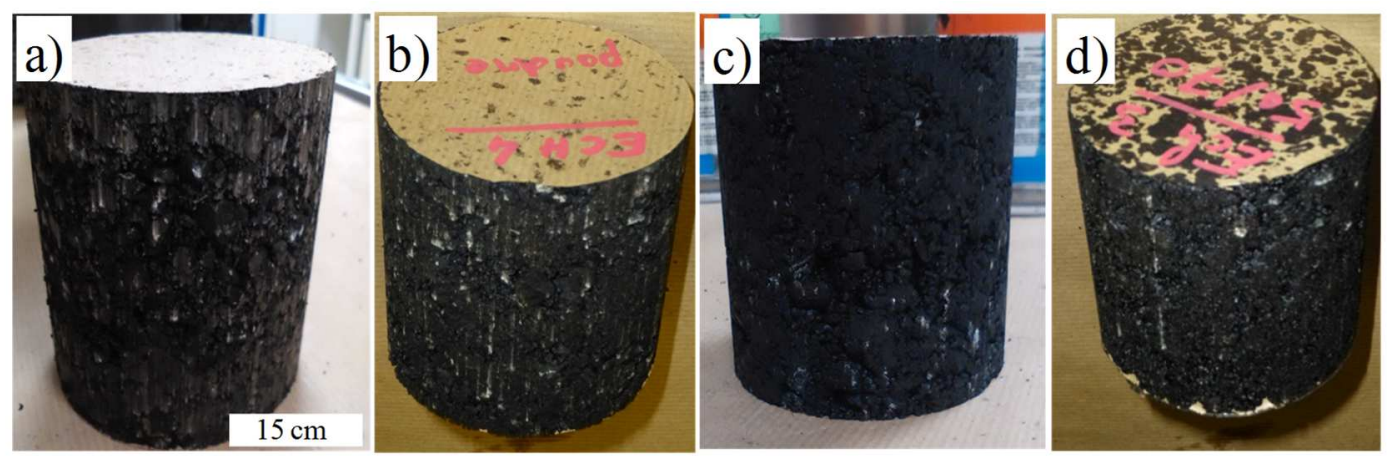

Figure 8. Examples of different asphalt mixes shaped as cylindrical columns dedicated to compression mechanical tests. a) $\mathrm{E} 2 \mathrm{f} @ \mathrm{SiO}_{2}$ based asphalt concrete obtained with the process 1, b) E2f@ $\mathrm{SiO}_{2}$ based asphalt concrete obtained with the process 2, c) pure bitumen (grade 160/220) asphalt concrete, d) pure bitumen (50/70) asphalt concrete.

The first information is that $\mathrm{E} 2 \mathrm{f} @ \mathrm{SiO}_{2}$ asphalt concrete obtained through both processes could be compacted and cylindrically shaped as the pure bitumen. Considering the columnar monolith resulting from the $\mathrm{E} 2 @ \mathrm{SiO}_{2}$ (process 1) (Fig. 8a) we noticed that, at the edges it was brittle, evidencing a lack of homogeneously distributed binder. This is not surprising as we already assessed the uncompleted bitumen release. The aspect of the cylindrical column obtained from the E2f@ $\mathrm{SiO}_{2}$ (process 2) (Fig.8b) was both shiny and exhibited good qualitative mechanical strength, as it was the case for the shaped cylinder with pure bitumen (Fig $8 \mathrm{c}$ and $8 \mathrm{~d}$ ). The results of the compression mechanical tests are summarized in Table 5.

Table 5. Summary of the compression tests for the diverse compacted asphalts.

\begin{tabular}{ccccccccc}
\hline $\begin{array}{c}\text { Nature of } \\
\text { the } \\
\text { cylinder }\end{array}$ & $\begin{array}{c}\text { Weight } \\
\text { of the } \\
\text { cylinder }\end{array}$ & $\begin{array}{c}\text { Height } \\
\text { of the } \\
\text { cylinder }\end{array}$ & $\begin{array}{c}\text { Diameters } \\
\text { of the } \\
\text { cylinder }\end{array}$ & $\begin{array}{c}\text { Apparent } \\
\text { densities } \\
\text { of the }\end{array}$ & $\begin{array}{c}\text { Void } \\
\text { percentage } \\
(\%)\end{array}$ & $\begin{array}{c}\text { Volume } \\
\text { of the } \\
\text { cylinder }\end{array}$ & $\begin{array}{c}\text { Maximum } \\
\text { pressure at } \\
\text { breaking }\end{array}$ & $\begin{array}{c}\text { Mechanical } \\
\text { resistance } \\
(\mathrm{MPa})\end{array}$ \\
\hline
\end{tabular}




\begin{tabular}{|c|c|c|c|c|c|c|c|c|}
\hline test pieces & $\begin{array}{l}\text { pieces } \\
\text { (g) }\end{array}$ & $\begin{array}{c}\text { pieces } \\
(\mathrm{mm})\end{array}$ & $\begin{array}{c}\text { pieces } \\
(\mathrm{mm})\end{array}$ & $\begin{array}{c}\text { cylinder } \\
\text { pieces } \\
(\mathrm{g} / \mathrm{cm})\end{array}$ & & $\begin{array}{c}\text { pieces } \\
\left(\mathrm{cm}^{3}\right)\end{array}$ & $(\mathrm{kN})$ & \\
\hline $\begin{array}{c}\text { Bitumen } \\
(160 / 220) \\
\text { asphalt } \\
\text { concrete }\end{array}$ & 1001 & 85.2 & 80 & 2.34 & 11.5 & 428.3 & 12.68 & 2.52 \\
\hline $\begin{array}{c}\mathrm{E} 2 \mathrm{f} @ \mathrm{SiO}_{2} \\
\text { Asphalt } \\
\text { concrete } \\
\text { (process 1) }\end{array}$ & 999.7 & 85 & 80 & 2.34 & 11.4 & 427.3 & 60.52 & 12.04 \\
\hline $\begin{array}{c}\mathrm{E} 2 \mathrm{f} @ \mathrm{SiO}_{2} \\
\text { Asphalt } \\
\text { concrete } \\
\text { (process 2) }\end{array}$ & 1001.1 & 87 & 80 & 2.30 & 13.3 & 437.3 & 25.44 & 5.06 \\
\hline $\begin{array}{c}\text { Bitumen } \\
(50 / 70) \\
\text { asphalt } \\
\text { concrete }\end{array}$ & 1001.2 & 84.2 & 80.1 & 2.36 & 10.6 & 424.3 & 29.07 & 5.77 \\
\hline
\end{tabular}

The first important result is that the compacted monolithic asphalts generated from the E2f@SiO 2 powder exhibit higher mechanical properties than the ones obtained with pure bitumen of identical penetration grade (160/220). It seems that the composite organic/inorganic nature of the $\mathrm{E} 2 \mathrm{f} @ \mathrm{SiO}_{2}$ powder induces better mechanical properties of the final asphalt concrete when compared with the ones reached with pure bitumen. The observation of improved performances with hybrid material is in agreement with the rheological results obtained before the addition of aggregates (on $\mathrm{E} 3 \mathrm{f} @ \mathrm{SiO}_{2}$ ). The asphalt concrete generated with the $\mathrm{E} 2 \mathrm{f} @ \mathrm{SiO}_{2}$ (process 1) offers a mechanical resistance of $12 \mathrm{MPa}$ and maximum pressure at breaking of $60 \mathrm{kN}$, even better than pure bitumen with a much lower penetration grade. However, we have to take some precaution here as the first process included a heating treatment at $160^{\circ} \mathrm{C}$ during 12 hours that could have induced some oxidation of the thin bitumen layer covering the aggregates. Nevertheless, if we consider the asphalt concrete obtained with $\mathrm{E} 2 \mathrm{f} @ \mathrm{SiO}_{2}$ powder and aggregates using the process 2, without this additional heating, we can see that the concrete exhibits the same mechanical properties than the asphalt concrete obtained with pure bitumen of grade 50/70 (mechanical resistance of 5.1-5.7 MPa and maximum pressure at breaking of 25-29 kN, see Table 5), and this evolution 
of the properties cannot be attributed to oxidation since both asphalt concretes have endured the same preparation treatment. As a conclusion, the $\mathrm{E} 2 \mathrm{f} @ \mathrm{SiO}_{2}$ powder and its mixing with aggregates following process 2 is really offering asphalt concretes with enhanced mechanical properties.

\section{Conclusion}

In a first step bitumen emulsion have been advantageously flocculated through a depletion process. Secondly, making use of sol-gel chemistry at almost neutral pH while employing a silicate solution as inorganic precursor, the flocculated emulsions have been mineralized at their outer surfaces, and a final spray drying technique is employed to both complete the silica polycondensation and promote an efficient drying of the final bitument@ $\mathrm{SiO}_{2}$ particles. These hybrid powders can resist up to $8 \mathrm{kPa}$ at $50{ }^{\circ} \mathrm{C}$ during at least 20 hours or $90^{\circ} \mathrm{C}$ during at least 14 hours without disrupting the particles core-shell nature or morphology, preserving the encapsulated bitumen, witnessing thus an outstanding storage property in big-bags. When heated at $100^{\circ} \mathrm{C}$ and crushed in a mortar, the bitumen containing the shell fragments exhibits a strong shear-tinning behavior at very low shear rates. If these fragments are dispersed in a Newtonian silicon oil, a strong shear thinning behavior also appears showing the role of the broken silica shell. The anisotropy of the silica fragment is assumed to play a major effect on the shear thinning behavior, particularly pronounced for the material $\mathrm{E} 3 \mathrm{f} @ \mathrm{SiO}_{2}$. Asphalt concretes have been generated and tested toward passive adhesion where the concrete obtained from the $\mathrm{E} 2 \mathrm{f} @ \mathrm{SiO}_{2}$ particles appears to be particularly stable. Upon compaction and shaped as cylinders, mechanical tests have been performed, where the concrete emerging from the $\mathrm{E} 2 \mathrm{f} @ \mathrm{SiO} 2$ particles is depicting outstanding mechanical resistance of $12 \mathrm{MPa}$ and a pressure at breaking of $60 \mathrm{kN}$. 
Beyond the final Bitumen@ $\mathrm{SiO}_{2}$ particles application as concrete binders, and due to the flocculation process, the pulverulent character of the powder has been minimized, while the bitumen can now be transported at ambient temperature without being dispersed in water anymore. The obtained bitumen powder is therefore an organic aggregate binder free of water that can be considered as the equivalent of "cement" which is a hydraulic binder commonly used in building. We think that such "water free" bitumens are particularly interesting because: they allow avoiding water transport, they exhibit higher stability than emulsions, they should improve the bitumen adhesion at mineral aggregates when employed as binders. The silica shells beyond offering the possibility to encapsulate the bitumen and allow drying the suspensions without destabilization, also play the role of mineral charges often added to bitumen. Therefore, we think such powders could help developing road pavement in geographic zones that are difficult to be reached.

\section{Ackowledgement}

This work has been performed through the funding of the ANRT PhD Cifre program number 2013/1190. The authors would like to thank Vincent Gaudefroy and Laure Boucard at IFSTTAR for providing bitumen emulsions E1 and E2. The authors also thank $\mathrm{D}^{\mathrm{r}}$ Pascal Massé and $\mathrm{D}^{\mathrm{r}}$ Armand Roucher for their willingness of performing the SEM investigations. We thank Mrs. Isabelle Ly for acquiring the Cryo-SEM/TEM images.

\section{References}

[1] D. Lesueur, The colloidal structure of bitumen: Consequences on the rheology and on the mechanisms of bitumen modification. Advances in Colloid and Interface Science 145 (2009) 42-82.

https://doi.org/10.1016/j.cis.2008.08.011

[2] I. Hénaut, J.-F. Argillier, C. Coustet, In 2004 AIChE Spring National Meeting, Conference Proceedings 2004, p 1912. 
[3] G. Thenoux, A. González, R. Dowling, Energy consumption comparison for different asphalt pavements rehabilitaion techniques used in Chile, Resour. Conser. Recycl. 49 (2007) 325-339.

https://doi.org/10.1016/j.resconrec.2006.02.005

[4] X. Gutierrez, F. Silva, M. Chirinos, J. Leiva, H. Rivas, Bitumen-in-water emulsions: an overview on formation, stability, and rheological properties. Journal of Dispersion Science and Technology 23 (2002) 405-418.

https://doi.org/10.1080/01932690208984213

[5] N. Romero, A. Cárdenas, M. Henríquez, H. Rivas, Viscoelastic properties and stability of highly concentrated bitumen in water emulsions. Colloids and Surfaces A: Physicochemical and Engineering Aspects 204 (2002) 271-284.

https://doi.org/10.1016/S0927-7757(02)00018-3

[6] S. Basu, K. Nandakumar, J.H. Masliyah, A study of oil displacement on model surfaces. J. Colloid Interface Sci 182 (1996) 82-94.

https://doi.org/10.1006/jcis.1996.0439

[7] W.R. Bailey, Asphalt pellets. Patent US233105, 2011.

[8] D. Saylak, Sulfur-coated asphalt pellets. Patent US4769288, 1987.

[9] H. M. Noel, Method for cooling and granulating asphalt. Patent US2062374, 1934.

[10] E.-A. Ross, Encapsulation of asphalt prills. Patent US5637350, 1995.

[11] K. Sockwell, Composition for pelletized bitumen and method for preparing the same. Patent US8404164, 2011.

[12] P. Anaclet, S. Mariotti, V. Julien, R. Backov, V. Schmitt. V. Development of dispersible and flowable powdered bitumen. J. Cleaner Produc. 141(2017) 940-946.

https://doi.org/10.1016/j.jclepro.2016.09.110

[13] S. Mariotti, M. Neuville, R. Backov, V. Schmitt, V.; Anaclet, P. Solid bitumen and method for obtaining the same. Patent FR1450249, 2014. PCT2015/FR050074.

[14] S.U. Pickering, CXCVI. - Emulsions. J. Chem. Soc., Trans. 91(1907) 2001-2021. https://doi.org/10.1039/CT9079102001

[15] L. Boucard, V. Schmitt, F. Farcas, V. Gaudefroy, Bitumen emulsions formulation and destabilisation process relationship: influence of salts addition. Road Materials and Pavement Design 16 (2015) 330-348.

https://doi.org/10.1080/14680629.2015.1030910

[16] Brinker, C.J.; Scherer, G. W. Sol-Gel Science: The Physics and Chemistry of Sol-Gel Processing, Academic Press, 1990.

[17] P. Partal, F. Martınez-Boza, B. Conde, C. Gallego Rheological characterisation of synthetic binders and unmodified bitumens. Fuel 78 (1999) 1-10

https://doi.org/10.1016/S0016-2361(98)00121-5

[18] G. Tsohos The influence of filler on the rheological and mechanical properties of bitumen Civil Engineering for Practicing and Design Engineers 5(6) (1986) 453-475

[19] B.O. Lerfald, I. Horvli, I. The Influence of Filler Materials on Rheology and Ageing of Filler-Bitumen-Mixes Road Materials and Pavement Design 4(4) (2003) 455-469

https://doi.org/10.1080/14680629.2003.9689959

[20] X. Ma, H. Chen, G. Cao, M. Xing, D. Niu Investigation of viscoelastoplastic behavior of asphalt mastic: Effects of shear strain rate and filler volume fraction Construction and

Building Materials 200 (2019) 559-569

https://doi.org/10.1016/j.conbuildmat.2018.12.080 
[21] F. Giustozzi, K. Mansour, F. Patti, M. Pannirselvam, F. Fiori Shear rheology and microstructure of mining material-bitumen composites as filler replacement in asphalt mastics Construction and Building Materials 171 (2018) 726-735

https://doi.org/10.1016/j.conbuildmat.2018.03.190

[22] P. K. Singh, S.K. Suman Influence of graphite on the physical and rheological properties of bituminous binder before and after short-term ageing Construction and Building Materials 192 (2018) 866-873

https://doi.org/10.1016/j.conbuildmat.2018.10.122

[23] J.-S. Chen, K.-Y. Lin Mechanism and behavior of bitumen strength reinforcement using fibers Journal of Materials Science 40 (2005) 87- 95

https://doi.org/10.1007/s10853-005-5691-4

[24] A. Simone, F. Mazzotta, S. Eskandarsefat, C. Sangiorgi, V. Vignali, C. Lantieri, G.

Dondi Experimental application of waste glass powder filler in recycled dense-graded asphalt mixtures 20 (2019) 592-607

https://doi.org/10.1080/14680629.2017.1407818

[25] M S Lebedev and N I Kozhukhova Rheological characteristics of bitumen mastic depending on composition and filler dispersity.

IOP Conf. Series: Journal of Physics: Conf. Series 1045 (2018) 012026

https://doi.org/10.1088/1742-6596/1045/1/012026

[26] R.A. Tarefder, M. Ahmad, Evaluating the relationship between permeability and moisture damage of asphalt concrete pavements. Journal of Materials in Civil Engineering 27(5) (2015) 04014172 


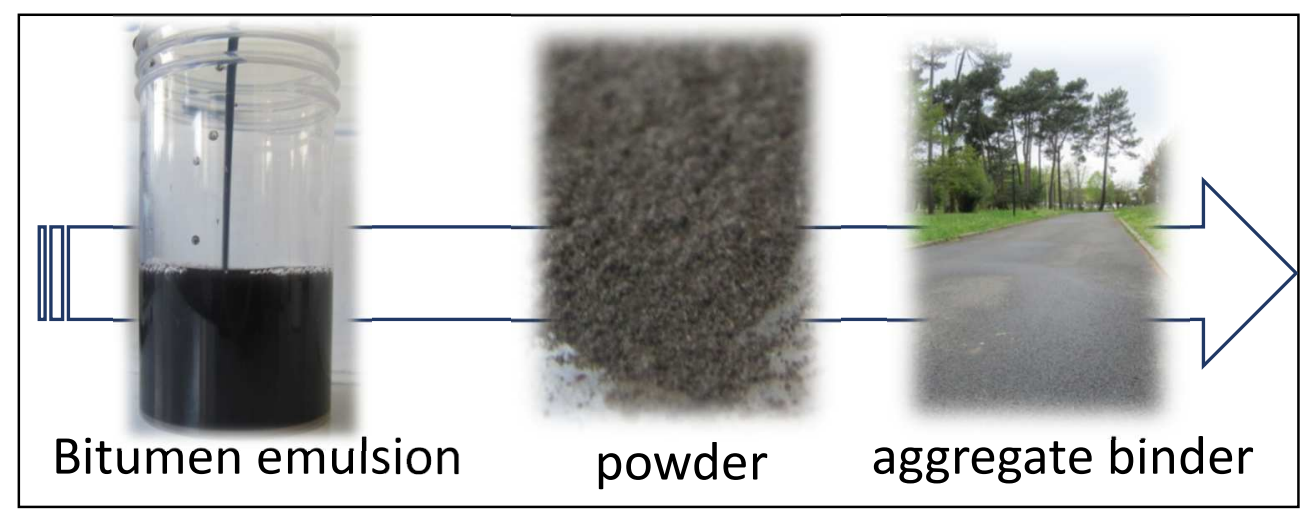

